\title{
Green Tea confers Protection on the Retina in MPTP Mice Model of Parkinson's Disease
}

\author{
Philemon Dauda Shallie $^{1^{*}}$, Koya Aderonke Kanyinsola ${ }^{2}$, \\ Oluwadamilola Faith Shallie ${ }^{1}$, Omowumi Femi-Akinlosotu ${ }^{3}$, Oluwole Ojo Alese ${ }^{4}$ \\ and Margaret Olutayo Alese ${ }^{5}$ \\ ${ }^{1}$ Department Anatomy, Olabisi Onabanjo University, Nigeria. \\ ${ }^{2}$ Department of Anatomy, Babcock University, Nigeria. \\ ${ }^{3}$ Department Anatomy, University of Ibadan, Nigeria. \\ ${ }^{4}$ Department Physiology, University of KwaZulu Natal, South Africa. \\ ${ }^{5}$ Department of Anatomy, Ekiti State University, Nigeria.
}

\begin{abstract}
Authors' contributions
This work was carried out in collaboration between all authors. Author PDS designed the study and wrote the protocol and the final draft of the manuscript. Author KAK managed the literature searches and wrote the first draft of the manuscript. Authors OFA, MOA and KAK managed the laboratory animals. Authors PDS, KAK, OFS, OFA and OOA performed the laboratory analyses. Authors MOA and OFS performed the statistical analysis. All authors read and approved the final manuscript.

Article Information

DOI: $10.9734 / A R R B / 2017 / 33328$

Editor(s):

(1) Xiao-Xin Yan, Department of Anatomy \& Neurobiology, Central South University Xiangya School of Medicine (CSU-XYSM),

Changsha, China.

(2) Paola Angelini, Department of Applied Biology, University of Perugia, Perugia, Italy. (3) George Perry, Dean and Professor of Biology, University of Texas at San Antonio, USA.

Reviewers:

(1) Mariateresa Giuliano, Univ of Campania "L. Vanvitelli", Italy.

(2) Taysa Bervian Bassani, Federal University of Paraná, Brazil. Complete Peer review History: http://www.sciencedomain.org/review-history/19622
\end{abstract}

Original Research Article

Received $10^{\text {th }}$ April 2017

Accepted $5^{\text {th }}$ June 2017

Published $20^{\text {th }}$ June 2017

\section{ABSTRACT}

Aim: This study investigated the impact of MPTP induced Parkinson's disease (PD) and the protective and/or curative effects of green tea on the retina.

Study Design: Twenty-five adult male mice (Mus musculus) weighing between 20-30 grams were used for this study. The mice were randomly placed into five groups of five mice each: A (Control; mice pellets), B (1Methyl -4-phenyl-2, 3, 6-tetrahydropyridine (MPTP) $10 \mathrm{mg} / \mathrm{kg}, \mathrm{IP}$ ), C (MPTP + Green tea (GT); $300 \mathrm{mg} / \mathrm{kg}$ GT orally), D (GT + MPTP), E (GT; $300 \mathrm{mg} / \mathrm{kg}$ ). 
Methodology: At the end of the experimental protocols, the eyes were excised weighed and processed to determine the neurotransmitter [Dopamine, Gamma amino butyric acid (GABA) and calcium ion $\left(\mathrm{CA}^{2+}\right)$ ] levels in the retina spectrophotometrically and histology of the retina using Hematoxylin and Eosin (H\&E) stain.

Results: The results showed significant $(P<0.005)$ reduction in the relative eye to body weight and increase in the retinal diameter in the MPTP group when compared with the control. Whereas treatments with green tea did not significantly $(P<0.005)$ increase the relative eye to body weight but intake of green tea alone does, while the retinal diameter is significantly reduced by pretreatment with green tea. The concentration of Calcium was significantly increased by MPTP and significantly reduced by green tea intake, whereas only the green tea alone and green tea cotreated groups significantly increased dopamine levels.

Conclusion: From our results we can preliminary conclude that green tea conferred protection on the retina against the adverse effects of MPTP in mice model of Parkinson's disease.

Keywords: Parkinson's disease; Retina; MPTP; neurotransmitters.

\section{INTRODUCTION}

Parkinson's disease (PD) is the second most common neurodegenerative disorder in the developed world, after Alzheimer's disease, with a prevalence of $0.3 \%$ and an estimated incidence of 8-18 per 100000 person years [1]. It is a multi-system disorder with a wide variety of motor and non-motor features. Prominent among the non-motor aspects of Parkinson's disease are mood disturbance [2-4], cognitive decline and dementia [5-8], sleep disorders [9], hyposmia [10] and autonomic failure [11-13]. In addition, visual symptoms are common, ranging from complaints of dry eyes and reading difficulties, through to perceptual disturbances (feelings of presence and passage) and complex visual hallucinations [14-18]. Such visual symptoms are a considerable cause of morbidity in Parkinson's disease [19] and, with respect to visual hallucinations, are an important predictor of cognitive decline as well as institutional care and mortality [20-23]. Evidence exists of visual dysfunction at several levels of the visual pathway in Parkinson's disease. This includes psychophysical, electrophysiological and morphological evidence of disruption of retinal structure and function. In agreement with the hypothesis that PD results from an imbalance of dopamine, it seems that visual deficits in PD are also caused by dopaminergic deficiency, resulting at least in part from reduced expression of tyrosine hydroxylase - the rate limiting enzyme in dopamine synthesis $[24,25]$. Indeed, some of the visual deficits experienced by patients with PD can be ameliorated by treatment with levodopa [26]. Environmental factors such as coffee drinking and smoking have been demonstrated to lower the risk of PD [27-29]. Several epidemiological studies have addressed the influence of drinking tea (Camellia sinensis) on the risk of PD. A case-control study of Chinese PD patients showed that regular tea drinking protects against PD [30]. Another study complimented the Chinese PD study showing a reduced risk for PD with tea consumption (two cups/day) [31]. Similarly, a large prospective study showed a reduced risk of incident PD in subjects who habitually drank three or more cups of tea per day [32]. A retrospective study associated drinking of more than three cups of tea per day with a delayed onset of motor symptoms in Israeli PD patients [33]. The effects of tea consumption on PD risk are currently the subject of considerable scientific debate as tea components, such as polyphenols, caffeine and theanine, have been demonstrated to be neuroprotective in PD [34,35]. The benefits of tea drinking are of relevance to PD as tea is one of the main contributors of dietary polyphenols in Western countries due to its regular consumption [36]. Thus, any evidence of the neuro-protective effects of polyphenols on PD could have a significant impact on public health. The work investigated the impact of MPTP induced Parkinson's disease and the protective and suppressive effects of green tea polyphenols on the retina.

\section{METHODOLOGY}

\subsection{Experimental Animals}

Twenty-five adult male mice (Mus musculus) weighing between 20-30 grams were used for this study. The animals' were housed in clean plastic cages, well ventilated environment with temperature ranging between $24-28^{\circ} \mathrm{C}$ in 12 hours light and 12 hours dark cycle. The animals were given standard mice pellets and water $a d$ 
libitum, and were allowed to acclimatize for four weeks before commencing the experimental protocols. MPTP was bought from Adooq Bioscience, while Lindberg Standardized Green Tea Extract purchased from Nutrition Express, CA, USA was used for the study. Each capsule contained $500 \mathrm{mg}$ of decaffeinated green tea extract standardized to contain $200 \mathrm{mg}$ of EGCG, 95\% polyphenols, $75 \%$ catechins, $40 \%$ EGCG. The extract was dissolved in distilled water to obtain a concentration of $300 \mathrm{mg} / \mathrm{kg} \quad(300$ $\mathrm{mg} / 1000 \mathrm{~g}$ ) body weight of the animal. While MRM Vegetarian Quercetin Extract was also used in the study to supplement the GTE and increase its bioavailability; It was purchased from Nutrition Express Torrance, CA, USA. Each capsule standardized to contain $500 \mathrm{mg}$ of QU995 (The world's purest Quercetin) which ensures superior bioavailability. The capsule was dissolved in distilled water to obtain a concentration of $6 \mathrm{mg} / \mathrm{kg}$ (1:5; Quercetin: GTE) [37].

The institutional committee on Animal Care and Use in Research, Education and Testing (ACURET) approval was obtained and the animal experiments were conducted according to the NIH Guide on Laboratory Animals for Biomedical Research (NIH, 1978) and ethical guidelines for investigation of experimental pain in conscious animals [38].

\subsection{Experimental Design}

Following the four weeks of acclimatization, the animals were randomly divided into five (5) groups of five (5) animals each as follows:

- Group A: (Positive Control Group) Mice were given dry food pellet and clean water ad libitum.

- Group B: (Negative Control Group) Mice were given $10 \mathrm{mg} / \mathrm{kg}$ of 1 Methyl -4-phenyl2,3,6-tetrahydropyridine (MPTP) per body weight intraperitoneally for 2 consecutive days; Four times per day with two hour intervals

- Group C: (Curative Group) Mice were given $10 \mathrm{mg} / \mathrm{kg}$ of MPTP per body weight intraperitoneally for 2 consecutive days followed by a seven (7) day oral treatment with $300 \mathrm{mg} / \mathrm{kg}$ of Green Tea Extract supplemented with $6 \mathrm{mg} / \mathrm{kg}$ of Quercetin (GT).

- Group D: (Protective Group) Mice were given $300 \mathrm{mg} / \mathrm{kg}$ of Green Tea Extract orally supplemented with $6 \mathrm{mg} / \mathrm{kg}$ of body weight of Quercetin for seven (7) days consecutively followed by a two (2) day administration of $10 \mathrm{mg} / \mathrm{kg}$ of MPTP intraperitoneally four (4) times per day with a\ two (2) hour intervals.

- Group E: (Treatment group) Mice were given $300 \mathrm{mg} / \mathrm{kg}$ of Green Tea Extract supplemented with $6 \mathrm{mg} / \mathrm{kg}$ of body weight of Quercetin orally for 7 consecutive days.

\subsection{Tissue Sample Preparation}

At the end of four weeks the rats were euthanized by administering $10 \mathrm{~g} / \mathrm{kg}$ body weight of Pentobarbital. The mice eyes were carefully dissected out and weighed, some were fixed in $10 \%$ formal-saline for routine histological procedures while retinal specimen were excised homogenized and centrifuge at 3500rpm for 15 minutes and the supernatant collected for neurotransmitters analyses.

\subsubsection{Removing the eye}

1. The mice were placed on a flat, dry and smooth surface.

2. Sterilized forceps with a curved, serrated tip were used.

3. The canthus was gently pressed with the forceps until the eyeball was displaced from the socket and the optic nerve was reachable.

4. The forceps was guided to the back of the eye, to pressed and hold the optic nerve firmly. This helped to lift the globe from the socket and to clamp the complete optic nerve.

5. The hand was made to move in circular pattern while holding the forceps in the direction with the least resistance while the mouse remains on the flat surface.

6. This action was performed with gradual increased speed until the optic nerve is constricted in two. Hence, the detached eyeball is removed.

7. The adhering fats and fascia were gently removed with the forceps.

\subsubsection{Protocol for the dissection of retinas}

1. The retinas were carefully dissected from the removed eyeballs.

2. The eyes were placed in a dish filled with D-PBS. The binocular dissecting microscope was used for the following steps.

3. For dissection of a retina, the anterior part of the eye, i.e. the lens and cornea, was 
first cut off. In order to facilitate the insertion of the scissors, the eyeball was fixed with tweezers and a hypodermic needle was used to make a small hole to indicate the incision starting point.

4. The short portion of the optic nerve on the posterior side of the eye was fixed by tweezers.

5. The eyeballs were squeezed in the opposite direction with another pair of tweezers to make the retina float out of the sclera.

6. Thin layer containing blood vessels was removed while the retinas was transferred into a fixative.

\subsection{Preparation of Histological Slides}

Tissue preparation was carried out using the conventional paraffin embedding method. Tissue sections were stained with Haematoxylin and Eosin (H\&E) to determine the general morphology [39].

\subsection{Procedure for the determination of neurotransmitters}

\subsubsection{Sample used: Retina}

\subsubsection{Procedure}

- Two grams of the sample was weighed in digestion tubes.

- One tablet of the selenium catalyst was added into the tube

- Ten milliliters of concentrated perchloric acid and concentrated nitric acid were added in the ratio of $1: 1$

- The tubes were placed in the digestion block and allowed to digest slowly.

- The digest was washed in a $1000 \mathrm{ml}$ volumetric flask and made up with distilled water.

- The washed samples were read with an Atomic Absorption Spectrophotometer (Spectronic 21D) using their respective lamp and wavelength [40].

Dopamine 520 nM; GABA 470 nM; Calcium 600 nM.

Calculation: meter reading $\mathrm{x}$ slope $\mathrm{x}$ dilution factor

\subsection{Photomicrography}

Photomicrographs were taken using Omax led digital Microscope.

\subsection{Statistical Analysis}

Data were analysed by comparing values for different treatment groups with the values for individual controls. Results were expressed as mean \pm SE. The significant differences among values were analysed using Graph Pad version 7 at $P$-value $<0.05$.

\section{RESULTS AND DISCUSSION}

Parkinson's disease is a progressive, degenerative disorder of the central nervous system, resulting from the loss of dopamineproducing brain cells, of which there is presently no cure. While the current treatments for Parkinson's are associated with serious side effects [41]. The results of our study revealed that PD significantly affected the relative eye weight $\left(F_{(4,5)}=58.51, p=0.0002\right)$ (See Fig. 1). Relative eye weight is a factor of body and eye weights; decrease in body weight or increase in eye weigh will results in increased relative organ weigh and vice versa. The lack of significance differences between the MPTP and the treated groups were due to the insignificant change in the body and eye weights between the groups. While the green tea only group showed significant increase in the relative weight of the eye when compared with the MPTP group. This increase in relative weight could be due to the observed decrease in body weight caused by green tea intake. Previous studies have shown that dietary EGCG at 1\% in C57BL/6 mice for 5 months [42], and at $0.5 \%$ and $1 \%$ in NZB mice for 4 weeks [43] prevented high fat diet-induced gain in body weight and fat mass. In both studies, food intake was the same between mice fed high fat and high fat plus EGCG. The inhibitory effect of EGCG on body weight and fat mass in high fat-induced mice has also been convincingly reported by other investigators [44, 45].The mechanisms appear to involve decreased energy/lipid absorption and lipogenesis, and increased fat oxidation [42-45].

We further investigated the morphology and morphometry of the retina and the results showed significant retinal hypertrophy as a result of the effect of the treatments $\left(F_{(4,10)}=75.42\right.$, $\mathrm{p}<0.0001)$, while Tukey's multiple comparisons test at $\alpha<0.05$ showed significant increase in the retinal diameter between the Control versus MPTP and Control versus MPTP +GT; While there was a lesser significant decrease in the retinal diameter between Control versus GT+ 
MPTP [Plate 1, Fig. F]. Significance differences were also observed between the MPTP group and the intervention groups (GT+ MPTP and GT+ MPTP). The retinal hypertrophy noticed in our study could be due to cellular adaptation in response to adverse effect of MPTP, which involves an increase in intracellular protein rather than intracellular fluid. While the group pretreated with $300 \mathrm{mg} / \mathrm{kg}$ of Green Tea extract supplemented with $6 \mathrm{mg} / \mathrm{kg}$ of Quercetin conferred a significant protection on the integrity of the retinal morphology. This protection has been attributed to the antioxidant activity and iron-chelating properties which prevent iron and alpha-synuclein accumulation in MPTP-treated mice [46].

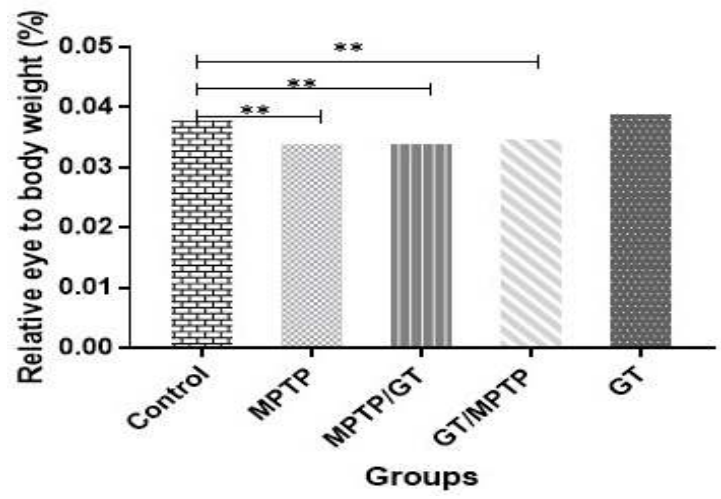

Fig. 1. Graph showing the mean relative eye weight

Fig. 1 shows the mean $\pm S E$ of relative eye weight of groups $A$ (control) (0.039 \pm 0.007$), B$ (MPTP) (0.035 \pm $0.007), C(M P T P+G T)(0.035 \pm 0.007), D(G T+$ MPTP) $(0.036 \pm 0.007), E(G T)(0.0395 \pm 0.007)$. The results of the one way ANOVA showed a significant effect of the treatments on the relative organ weight of

the eye $\left(F_{(4,5)}=58.51, p=0.0002\right)$, while Tukey's

multiple comparisons test at $\alpha<0.05$ showed significant weight decrease between the Control $(0.039 \pm 0.007)$ versus MPTP $(0.035 \pm 0.007)$; Control

$(0.039 \pm 0.007)$ versus MPTP $+G T(0.035 \pm 0.007)$ and Control (0.039 \pm 0.007$)$ versus GT + MPTP $(0.036$ $\pm 0.007)$. Significance differences were not observed between the MPTP group and the intervention groups

(GT+ MPTP and GT+ MPTP).

In addition the study also assessed the retinal concentrations of dopamine, GABA and $\mathrm{Ca}^{2+}$.The results of the one way ANOVA showed a significant effect of the treatments on the dopamine concentration in the eye $\left(F_{(4,5)}\right.$ $=49.07, \quad \mathrm{p}=0.0003$ ), while Tukey's multiple comparisons test at $\alpha<0.05$ showed significant increase in dopamine concentration between the Control versus MPTP +GT; Control versus GT+ MPTP. Significance differences were also observed between the MPTP group and the intervention groups (GT+ MPTP and GT+ MPTP) (Fig. 2).

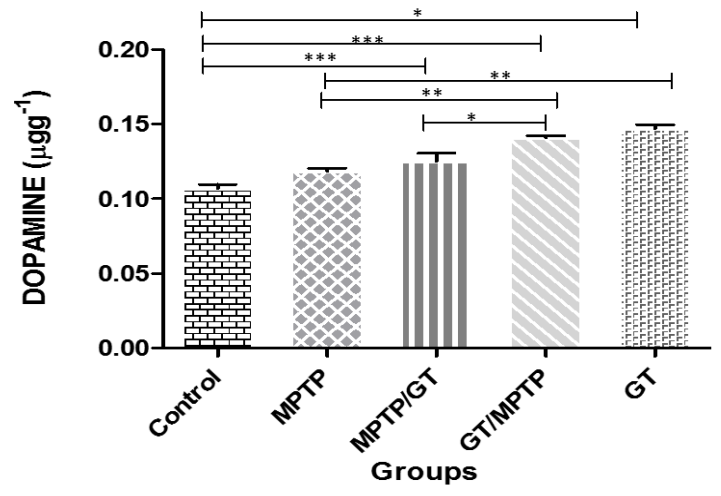

Fig. 2. Graph showing the dopamine levels in the homogenate of retina of mice

Fig. 2 shows the mean $\pm S E$ of Dopamine concentration in the eye of groups $A$ (control) $(0.107 \pm$ $0.001), B(M P T P)(0.119 \pm 0.003), C(M P T P+G T)$

$(0.125 \pm 0.003), D(G T+M P T P)(0.141 \pm 0.003), E$

(GT) $(0.147 \pm 0.003)$. The results of the one way ANOVA showed a significant effect of the treatments on the dopamine concentration in eye $\left(F_{(4,5)}=49.07\right.$, $p=0.0003$ ), while Tukey's multiple comparisons test at $\alpha<0.05$ showed significant increase in dopamine concentration between the Control $(0.107 \pm 0.003)$ versus MPTP +GT (0.125 \pm 0.003$)$; Control (0.107 \pm $0.003)$ versus $G T+M P T P(0.141 \pm 0.003)$.

Significance differences were also observed between the MPTP group and the intervention groups (MPTP + $G T$ and $G T+M P T P$ ) and between $G T+M P T P$ versus $G T+M P T P$ and $G T+M P T P$ versus $G T$.

The increase in dopamine noticed in the MPTP group could be due to the fact that dopamine is believed to contribute to the degeneration of dopamine-containing neurons in the brain. The elevated extracellular dopamine recorded in this study may not be unconnected to inactivation of the dopamine transporter gene which is necessary for the sporadic development of severe symptoms of dyskinesia concomitant with apoptotic death of striatal dopamine-responsive $\mathrm{y}$-aminobutyric acidergic neurons [47]. The advancement of the "triple hit" hypothesis assumes that too much calcium, plus a build-up of $\alpha$-SNCA and increased dopamine within the cells, may trigger neuronal death in PD. Experimental observations confirmed that an increase in calcium concentration inside neurons when accompanied by intracellular accumulation of misfolded proteins, initiate apoptosis when a certain physiological threshold is crossed. The process of programmed cell death may be also accelerated by excitotoxicity due to excessive 
neurotransmitter level [48]. While green tea intake also increased dopamine levels in all the treated groups. These increase could be due to theanine, which makes up 1-2\% of the dry weight of green tea, because drinking two to four cups of green tea every day is equivalent to taking approximate 50-200 mg of I-theanine [49]. L-theanine is able to exert its effect on dopamine because of its ability to cross the blood-brain barrier and increase dopamine levels in the brain [50]. It has also been shown to exert neuroprotective effects in animal models possibly through its antagonistic effects on group 1 metabotrophic glutamate receptors [51].

We also observed significant effect of the treatments on the GABA concentration in the eye $\left(F_{(4,5)}=7.114, p=0.027\right.$ ) (See Fig. 3). Our results showed that green tea significantly increase GABA level in the mice that took green tea only and those that took green tea before Parkinson's disease induction (pre-treated group). These results are in agreement with previous preclinical studies that suggested that L-theanine increases a number of neurotransmitters including GABA level [52, 53 and 54]. While the lack of significant increase noticed in the MPTP and the post-treated groups in this study could be due to the fact that the concentration of GABA in Parkinson's disease depends on the amount that is synthesized and released, as well as on the activity of enzymes and cofactors involved in its processing [55].In neurodegenerative disease the excessive neuronal activity is firstly tuned by increased GABA inhibition [56-58]. This acts as a physiological control mechanisms within the nervous system, and that deficiency in this mechanism may be responsible for the progressive decline in brain function and neurodegeneration.
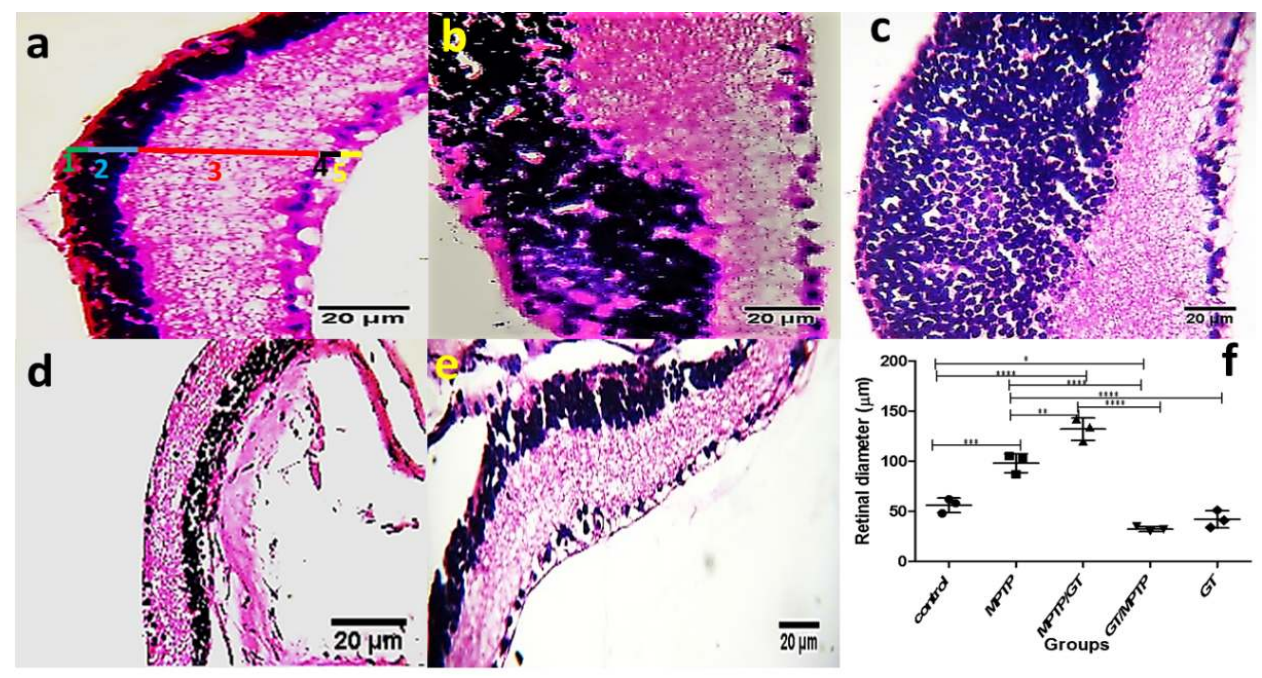

Plate 1. Showing the photomicrographs of mice retina stained with H\&E X400: (a) Retina of control group showing 1. Pigment epithelium and photoreceptor cells layers (green band); 2.

Outer nuclear layer, outer plexiform layer and inner nuclear layer (blue band); 3. Inner plexiform layer (red band); 4. Ganglion cell layer (black band); 4. Nerve fibre layer and inner limiting membrane (yellow band). (b) Retina of MPTP treated mice with hypertrophied/ diffused nuclear layers and disrupted inner limiting membrane. (c)Retina of MPTP+GT treated mice with hypertrophied/ diffused nuclear layers, increased ganglion cell layer density and disrupted inner limiting membrane. (d) Retina of GT+MPTP treated mice with preserved and relatively shrinked nuclear layers and intact inner limiting membrane.(e)Retina of GT treated mice with preserved and significantly shrinked nuclear layers and intact inner limiting membrane.(f) Scattered diagram showing the mean diameter of the retina of experimental groups; groups A

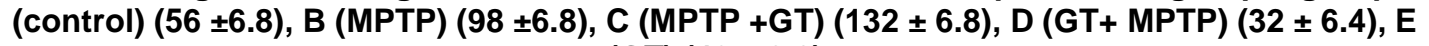

$$
\text { (GT) }(42 \pm 6.6)
$$

The results of the one way ANOVA showed a significant effect of the treatments on the retinal diameter $\left(F_{(4,10)}\right.$ $=75.42, p<0.0001)$, while Tukey's multiple comparisons test at $\alpha<0.05$ showed significant increase in the retinal diameter between the Control (56 \pm 6.8 ) versus MPTP $(98 \pm 6.8)$ and Control $(56 \pm 6.8)$ versus MPTP +GT; while there was a lesser significant decrease in the retinal diameter between Control(56 \pm 6.8$)$ versus GT+ MPTP (32 \pm 6.4). Significance differences were also observed between the MPTP group and the intervention groups (GT+ MPTP and GT+MPTP) 


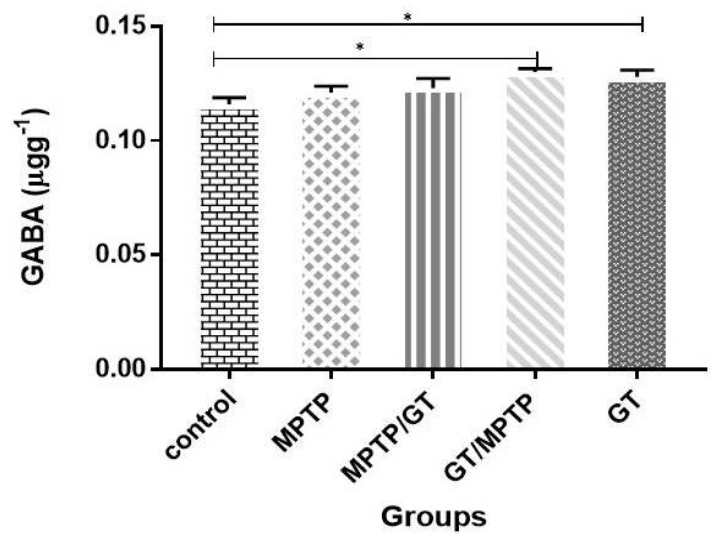

Fig. 3. Graph showing GABA concentration in the homogenate of retina of mice

Fig. 3 shows the mean \pm SE of GABA concentration in the eye of groups $A$ (control) $(0.116 \pm 0.0029), B$ (MPTP) (0.1205 \pm 0.0029$), C(M P T P+G T)(0.123 \pm$ 0.0029), $D(G T+M P T P)(0.130 \pm 0.0029), E(G T)$ $(0.1275 \pm 0.0029)$. The results of the one way ANOVA showed a significant effect of the treatments on GABA concentration in the eye $\left(F_{(4,5)}=7.114, p=0.027\right)$, while Tukey's multiple comparisons test at $\alpha<0.05$ showed significant increase in GABA concentration between the Control $(0.116 \pm 0.0029)$ versus GT+ MPTP $(0.130$ $\pm 0.0029)$ and Control $(0.116 \pm 0.0029)$ versus $G T$ $(0.1275 \pm 0.0029)$. There were no significance differences between the MPTP group and the intervention groups (GT+ MPTP and GT+ MPTP)

Calcium homeostasis is maintained in part by complex hormonal systems. Our results showed that the calcium level responded significant to the effect of the treatments $\left(F_{(4,5)}=3346, p<0.0001\right)$ (Fig. 3). The results above clearly showed that MPTP administration increased the levels of $\mathrm{Ca}^{2+}$ in the retina, whereas both pre and posttreatment with $300 \mathrm{mg} / \mathrm{kg}$ of green tea extract supplemented with $6 \mathrm{mg} / \mathrm{kg}$ of Quercetin decreased its concentrations. Increased intracellular calcium, in association with excess nitric oxide and excitatory amino acids, is involved in several neurodegenerative diseases, including Parkinson's disease [59], and that maintaining calcium homeostasis in the cell is anchored on mitochondrial integrity. However excessive mitochondrial calcium accumulation can also results in loss of mitochondrial transmembrane potential and uncoupling of respiratory chain; increasing the generation of oxygen and nitrogen reactive species. Impairment of mitochondrial function can compromise ATP production and, consequently, lead to depletion of ATP stores and failure of ion homeostasis, including regulation of calcium concentration [60-61]. Removal of the divalent calcium ions from the mitochondria and cytoplasm requires, however, significant amounts of energy (and time), and therefore, calcium overloaded neurons have high energy requirements [58]. Long-lasting intracellular calcium load results in mitochondrial oxidative stress that can exacerbate neurodegeneration [58]. Flavonoids (major components of green tea) were shown to protect from oxidative stress by three distinct mechanisms: Directly affecting GSH metabolism, acting as antioxidants, and maintaining low Calcium levels despite high levels of ROS. Naturally occurring flavonoids are able to prevent mitochondrial lipid peroxidation and can inhibit MPTP opening [62]. Moreover, flavonoids are endowed with free radical scavenging and antioxidant properties [63,64], which can also contribute to the inhibitory effect of flavonoids towards MPTP opening. This study suggests that some flavonoids are able to interact with mitochondrial physiology, exerting neuroprotective actions, especially when able to target the MPTP complex.

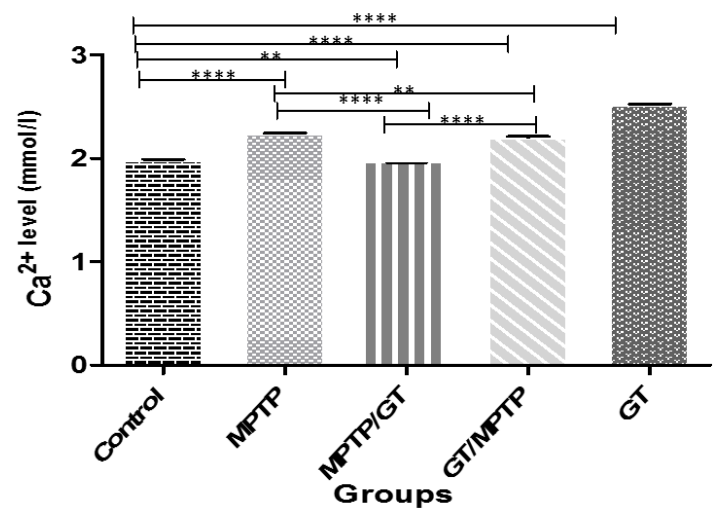

Fig. 4. Graph showing calcium ion $\left(\mathrm{Ca}^{2+}\right)$ concentration in the homogenate of retina of mice

Fig. 4 shows the mean \pm SE of $\mathrm{Ca}^{2+}$ concentration in the eye of groups $A$ (control) (1.985 \pm 0.015$), B$ (MPTP) $(2.240 \pm 0.01), C(M P T P+G T)(1.950 \pm 0.01)$, $D(G T+M P T P)(2.20 \pm 0.0), E(G T)(2.525 \pm 0.025)$.

The results of the one way ANOVA showed a significant effect of the treatments on calcium ion concentration in the eye $\left(F_{(4,5)}=3346, p<0.0001\right)$, while Tukey's multiple comparisons test at $\alpha<0.05$ showed significant increase in $\mathrm{Ca}^{2+}$ concentration between the Control $(1.985 \pm 0.006)$ versus MPTP (2.240 \pm 0.01$)$; Control (1.985 \pm 0.006$)$ versus MPTP $+G T(1.950 \pm 0.01)$; Control (1.985 \pm 0.006$)$ versus GT+ MPTP (2.20 \pm 0.0$)$ and Control (1.985 \pm 0.006$)$ versus GT (2.525 \pm 0.025$)$. Significance differences were also observed between the MPTP group and the intervention groups (GT+ MPTP and GT+ MPTP) 


\section{CONCLUSION}

From our results we can preliminary conclude that green tea confers protection against the adverse effects of MPTP in mice model of Parkinson's disease probably by preventing mitochondrial lipid peroxidation and inhibition of MPTP opening.

\section{CONSENT}

All authors declare that written informed consent was obtained from the patient (or other approved parties) for publication of this paper and accompanying images.

\section{ETHICAL APPROVAL}

As per international standard or university standard, written approval of ethics committee has been collected and preserved by the authors.

\section{COMPETING INTERESTS}

Authors have declared that no competing interests exist.

\section{REFERENCES}

1. De Lau LM, Breteler MM. Epidemiology of Parkinson's disease. Lancet Neurol. 2006; 5(6):525-535.

2. Cummings JL, Masterman DL. Depression in patients with Parkinson's disease. Int $\mathrm{J}$ Geriatr Psychiatry. 1999;14:711-8.

3. Lemke MR, Fuchs G, Gemende I, Herting $B$, Oehlwein $\mathrm{C}$, Reichmann $\mathrm{H}$, et al. Depression and Parkinson's disease. J Neurol. 2004;251(Suppl6):VI/24-7.

4. Martinez-Martin $P$, Schapira AHV, Stocchi $F$, Sethi K, Odin P, MacPhee G, et al. Prevalence of nonmotor symptoms in Parkinson's disease in an international setting; study using nonmotor symptoms questionnaire in 545 patients. Mov Disord. 2007;22:1623-9.

5. Levy $\mathrm{G}$, Jacobs DM, Tang MX, Cote LJ, Louis ED, Alfaro B, et al. Memory and executive function impairment predict dementia in Parkinson's disease. Mov Disord. 2002;17:1221-6.

6. Aarsland D, Litvan I, Salmon D, Galasko D, Wentzel-Larsen T, Larsen JP. Performance on the dementia rating scale in Parkinson's disease with dementia and dementia with Lewy bodies: Comparison with progressive supranuclear palsy and Alzheimer's disease. J Neurol Neurosurg Psychiatry. 2003;74:1215-20.

7. Foltynie T, Brayne CEG, Robbins TW, Barker RA. The cognitive ability of an incident cohort of Parkinson's patients in the UK. The Campaign study. Brain. 2004; 127:550-60.

8. Janvin CC, Larsen JP, Salmon DP, Galasko D, Hugdahl K, Aarsland D.Cognitive profiles of individual patients with Parkinson's disease anddementia: Comparison with dementia with lewy bodies and Alzheimer's disease. Mov Disord. 2006b;21:337-42.

9. Comella CL. Sleep disturbances and excessive daytime sleepiness in Parkinson disease: An overview. J Neural Transm 2006;70(Suppl):349-55.

10. Bohnen NI, Gedela S, Kuwabara H, Constantine GM, Mathis CA, Studenski $\mathrm{SA}$, et al. Selective hyposmia and nigrostriatal dopaminergic denervation in Parkinson's disease. J Neurol. 2007;254: 84-90.

11. Allcock LM, Kenny RA, Burn DJ. Clinical phenotype of subjects with Parkinson's disease and orthostatic hypotension: Autonomic symptom and demographic comparison. Mov Disord. 2006;21:1851-5.

12. Lucetti C, Gambaccini $G$, Del Dotto $P$, Ceravolo R, Logi C, Rossi G, et al. Longterm clinical evaluation in patients with Parkinson's disease and early autonomic involvement. Parkinsonism Relat Disord. 2006;12:279-83.

13. Wullner U, Schmitz-Hubsch T, Antony G, Fimmers R, Spottke A, Oertel WH, et al. Autonomic dysfunction in 3414 Parkinson's disease patients enrolled in the German network on Parkinson's disease (KNP e.V.): the effect of ageing. Eur $\mathrm{J}$ Neurol. 2007;14:1405-8.

14. Repka MX, Claro MC, Loupe DN, Reich SG. Ocular motility in Parkinson's disease. J Pediatr Ophthalmol Strabismus. 1996; 33:144-7.

15. Fenelon G, Mahieux F, Huon R, Ziegler M. Hallucinations in Parkinson's disease: Prevalence, phenomenology and risk factors. Brain. 2000;123:733-45.

16. Barnes J, David AS. Visual hallucinations in Parkinson's disease: A reviewand 
phenomenological survey. J Neurol Neurosurg Psychiatry. 2001;70:727-33.

17. Holroyd S, Currie L, Wooten GF. Prospective study of hallucinations and delusions in Parkinson's disease. J Neurol Neurosurg Psychiatry. 2001;70:734-8.

18. Biousse V, Skibell BC, Watts RL, Loupe DN, Drews-Botsch C, Newman NJ. Ophthalmologic features of Parkinson's disease. Neurology. 2004;62:177-80.

19. Aarsland D, Larsen JP, Karlsen K, Lim NG, Tandberg E. Mental symptoms in Parkinson's disease are important contributors to caregiver distress. Int $\mathrm{J}$ Geriatr Psychiatry. 1999;14:866-74.

20. Goetz CG, Stebbins GT. Risk factors for nursing home placement inadvanced Parkinson's disease. Neurology. 1993;43: 2227-9.

21. Goetz CG, Stebbins GT. Mortality and hallucinations in nursing home patients with advanced Parkinson's disease. Neurology. 1995;45:669-71.

22. Aarsland D, Larsen JP, Tandberg E, Laake K. Predictors of nursing home placement in Parkinson's disease: A populationbased, prospective study. J Am Geriat Soc. 2000; 48:938-42.

23. Goetz CG, Fan W, Leurgans S, Bernard B, Stebbins GT. The malignant course of 'benign hallucinations' in Parkinson disease. Arch Neurol. 2006;63:713-6.

24. Santano C, Pérez de Lara M, Pintor J. In studies on experimental models (Eds Basu S. \& Wiklund L.) Humana Press, New York. 2011;221-250.

25. Archibald NK, Clarke MP, Mosimann UP, Burn DJ. The retina in Parkinson's disease. Brain. 2009;132:1128-1145.

26. Onofrj M, Ghilardi MF, Basciani M, Gambi D. Visual evoked potentials in Parkinsonism and dopamine blockade reveal a stimulus-dependent dopamine function in humans. J. Neurol. Neurosurg. Psychiatry. 1986;49:1150-1159.

27. Hernan MA, Takkouche B, CaamanoIsorna F, GestalOtero JJ. A meta-analysis of coffee drinking, cigarette smoking and the risk of Parkinson's disease. Ann Neurol. 2002;52(3):276-284.

28. Costa J, Lunet N, Santos C, Santos J, Vaz-Carneiro A. Caffeine exposure and the risk of Parkin M. Caruana, Vassallo N. son's disease: A systematic review and meta-analysis of observational studies. J Alzheimers Dis. 2010;20:221-238.

29. Wirdefeldt K, Adami HO, Cole P, Trichopoulos D, Mandel J. Epidemiology and etiology of Parkinson's disease: A review of the evidence. Eur J Epidemiol. 2011;26(Suppll):1-58.

30. Chan DK, Woo J, Ho SC, Pang CP, Law LK, Ng PW, Hung WT, Kwok T, Hui E, Orr K, Leung MF, Kay R. Genetic and environmental risk factors for Parkinson's disease in a Chinese population. J Neurol Neurosurg Psychiatry. 1998;65(5):781784.

31. Checkoway H, Powers K, Smith-Weller T, Franklin GM, Longstreth WT, Swanson PD. Parkinson's disease risks associated with cigarette smoking, alcohol consumption, and caffeine intake. Am J Epidemiol. 2002;155(8):732-738.

32. Hu G, Bidel S, Jousilahti P, Antikainen R, Tuomilehto J. Coffee and tea consumption and the risk of Parkinson's disease. Mov Disord. 2007;22(15):2242-2248.

33. Kandinov B, Giladi N, Korczyn AD. Smoking and tea consumption delay onset of Parkinson's disease. Parkinsonism Relat Disord. 2009;15(1):41-46.

34. Tan LC, Koh WP, Yuan JM, Wang R, Au WL, Tan JH, Tan EK, Yu MC. Differential effects of black versus green tea on risk of Parkinson's disease in the Singapore Chinese Health Study. Am J Epidemiol. 2008;167(5):553-560.

35. Quintana BJ, Allam MF, Del Castillo AS, Navajas RF. Parkinson's disease and tea: a quantitative review. J Am Coll Nutr. 2009; 28(1):1-6.

36. Erdman JW, Balentine D, Arab L, Beecher G, Dwyer JT, Folts J, Harnly J, Hollman P, Keen CL, Mazza G, Messina M, Scalbert A, Vita J, Williamson G, Burrowes J. Flavonoids and heart health. J Nutr. 2007; 137(3 Suppl 1):737.

37. Henning SM, Wang MP, Abgaryan N, Vicinanza R, de Oliveira DM, Zhang YJ, Lee RP, Carpenter CL, Aronson WJ, Heber D. Mol. Nutr. Food Res. 2013;57: 483-492.

38. Zimmermann M. Ethical guidelines for investigations of experimental pain in conscious animals. Pain. 1983;16:109110.

39. Drury RAB, Wallington EA. Carleton's histological technique, $5^{\text {th }}$ ed. Oxford, UK: 
Oxford University Press, Oxford. Wenk modification is substitution of acetaldehyde for paraldehyde. Wenk PA. J. Histotechnology. 1996;19(4):353-355.

40. Preer JR, Rosen WG. Lead and cadmium content of urban garden vegetables. Trace Subst Environ Health. 1977;11:399-405.

41. Shuhong Guo, Jingqi Yan, Tangbin Yang, Xianqiang Yang, Erwan Bezard, Baolu Zhao. Protective effects of green tea polyphenols in the 6-OHDA rat model of parkinson's disease through inhibition of ROS-NO pathway. Biological Psychiatry. 2007;62(12):1353-1362.

42. Wolfram S, Raederstorff D, Wang $Y$, Teixeira SR, Elste V, Weber P. TEAVIGO (epigallocatechin gallate) supplementation prevents obesity in rodents by reducing adipose tissue mass. Ann Nutr Metab. 2005;49:54-63.

43. Klaus S, Pultz S, Thone-Reineke C, Wolfram S. Epigallocatechin gallate attenuates diet-induced obesity in mice by decreasing energy absorption and increasing fat oxidation. Int $\mathrm{J}$ Obes (Lond). 2005;29:615-23.

44. Bose M, Lambert JD, Ju J, Reuhl KR, Shapses SA, Yang CS. The major green tea polyphenol, (-)-epigallocatechin-3gallate, inhibits obesity, metabolic syndrome, and fatty liver disease in highfat-fed mice. J Nutr. 2008;138:1677-83.

45. Murase T, Nagasawa A, Suzuki J, Hase T, Tokimitsu I. Beneficial effects of tea catechins on diet-induced obesity: Stimulation of lipid catabolism in the liver. Int J Obes Relat Metab Disord. 2002; 26:1459-64.

46. Mandel SA, Avramovich-Tirosh $\mathrm{Y}$, Reznichenko L, et al. Multifunctional activities of green tea catechins in neuroprotection: Modulation of cell survival genes, iron-dependent oxidative stress and PKC signaling pathway, Neuro Signals. 2005;14(1-2):46-60.

47. Cyr M, Beaulieu J, Laakso A, Sotnikova T, Yao W, Bohn M, Gainetdinov R, Caron G. Sustained elevation of extracellular dopamine causes motor dysfunction and selective degeneration of striatal GABAergic neurons. PNAS. 2003;100(19): 11035-11040.

48. Mosharov EV, Larsen KE, Kanter E, Phillips KA, Wilson K, Schmitz $\mathrm{Y}$, et al. Interplay between cytosolic dopamine, calcium, and alphasynuclein causes selective death of substantia Nigra neurons. Neuron. 2009;62:218-229.

49. Kobayashi $K$, Nagato $\mathrm{Y}$, Aoi $\mathrm{N}$, et al. Effects of I-theanine on the release of $\alpha$ brain waves in human volunteers. Nippon Nögeikagaku Kaishi. 1998;72:153-157.

50. Foxe JJ, Morie KP, Laud PJ, Rowson MJ, de Bruin EA, Kelly SP. Assessing the effects of caffeine and theanine on the maintenance of vigilance during a sustained attention task. Neuropharmacology. 2012;62(7):2320-7.

51. Kakuda Nozawa A, Sugimoto A, Nino H. Inhibition by theanine of binding of $[3 \mathrm{H}]$ AMPA, [3H] Kainate, and [3H] MDL 105,519 to glutamate receptors. Biosci Biotech Biochem. 2002;66:2683-2686.

52. Kimura K, Ozeki M, Juneja LR, Ohira H. ITheanine reduces psychological and physiological stress responses. Biol Psychol. 2007;74:39-45.

53. Yokogoshi H, Kobayashi M, Mochizuki, Terashima T. Effect of theanine, rglutamylethylamide, on brain monoamines and striatal dopamine release in conscious rats. Neurochemical Research. 1998a;23: 667-673.

54. Yokogoshi H, Mochizuki M, Saitoh K. Theanine-induced reduction of brain serotonin concentration in rats. Biosci Biotech Biochem. 1998b;62:816-817.

55. Richerson GB, Wu Y. Dynamic equilibrium of neurotransmitter transporters: Not just for reuptake anymore. J. Neurophysiol. 2003;90:1363-1374.

56. Petroff OA. Book Review: GABA and glutamate in the human brain. Neuroscientist. 2002;8:562-573.

57. Moore DJ, West AB, Dawson VL, Dawson TM. Molecular pathophysiology of Parkinson's disease. Ann. Rev. Neurosci. 2005;28:57-87.

58. Surmeier DJ, Schumacker PT. Calcium, bioenergetics, and neuronal vulnerability in Parkinson's disease. J. Biol. Chem. 2013; 288:10736-10741.

59. Ray P. Calcium and disease: Hypertension. Organ Calcification and Shock vs. Respiratory Energy; 2009.

Available:http://raypeat.com/articles/article s/calcium.shtml

60. Nicholls DG. Mitochondrial dysfunction and glutamate excitotoxicity studied in primary 
neuronal cultures. Curr. Mol. Med. 2004;4: 149-177.

61. Nicholls DG, Budd SL. Mitochondria and neuronal glutamate excito- toxicity. Biochim. Biophys. Acta. 1998;1366:97112.

62. Santos AC, Uyemura SA, Lopes JL, Bazon $\mathrm{JN}$, Mingatto FE, Curti C. Effect of naturally occurring flavonoids on lipid peroxidation and membrane permeability transition in mitochondria. Free Radic. Biol. Med. 1998; 24:1455-1461.

63. Schroeter H, Williams RJ, Matin R, Iversen L. and Rice-Evans CA. Phenolic antioxidants attenuate neuronal cell death following uptake of oxidized low- density lipoprotein. Free Radic. Biol. Med. 2000; 29:1222-1233.

64. Rice-Evans C. Flavonoid antioxidants. Curr. Med. Chem. 2001;8:797-807.

(c) 2017 Shallie et al.; This is an Open Access article distributed under the terms of the Creative Commons Attribution License (http://creativecommons.org/licenses/by/4.0), which permits unrestricted use, distribution, and reproduction in any medium, provided the original work is properly cited.

Peer-review history:

The peer review history for this paper can be accessed here: http://sciencedomain.org/review-history/19622 